\title{
DESAFIOS PARA IMPLANTAR UM SISTEMA DE CUSTOS NO TRIBUNAL REGIONAL DO TRABALHO NO RIO GRANDE DO SUL
}

\author{
CHALLENGES TO IMPLANT A COST SYSTEM AT THE REGIONAL
} LABOUR COURT IN RIO GRANDE DO SUL

\section{Giovani Pasa Colussi}

Graduado em Ciências Contábeis (Universidade Federal do Rio Grande do Sul/ Brsil).E-mail: giovani_colussi@hotmail.com.

\section{Ângela Rozane Leal de Souza}

Doutora em Agronegócios (Universidade Federal do Rio Grande do Sul, Brasil). Professora (Universidade Federal do Rio Grande do Sul (Porto Alegre/Brasil).E-mail: angela.rsl@gmail.com. 


\section{RESUMO}

Com a obrigatoriedade para implantação de um sistema de custos no Tribunal Regional do Trabalho da 4a Região (TRT4) até 2020, o presente estudo tem como questão problema detectar quais informações o sistema de custos deverá gerar para os gestores do TRT4. Esta pesquisa objetiva demonstrar as diretrizes do Sistema de Custos da Justiça do Trabalho (SICJT) e as necessidades do Sistema de Custos do Tribunal Regional do Trabalho da 4a Região (SICTRT4) apontadas pelos gestores do Tribunal. A pesquisa é definida como qualitativa, descritiva e estudo de caso. Foram realizadas entrevistas com os gestores do TRT4 e analisados documentos referentes ao SICJT. Para o SICTRT4, foram apontados: (a) o método de custeio: custeio direto ou ABC; (b) o rateio dos custos indiretos: na área judiciária e administrativa; (c) os benefícios: ganho de produtividade, comparabilidade, maior transparência; (d) as informações geradas: custo do processo julgado pelas instâncias, relatórios e informações confiáveis; e (e) os centros de custos: unidades do $1^{\circ}$ e $2^{\circ}$ grau, apoio judiciário, apoio administrativo e as áreas autônomas. Os desafios encontrados são orçamentários, tais como a falta de conhecimento e divulgação do sistema pela administração, a resistência a mudanças e a falta de sistemas específicos.

Palavras-chave: Sistema de custos. Custos aplicados ao setor público. TRT4.

\section{ABSTRACT}

With the obligation to implant a cost system in the Regional Labor Court of the Fourth Region (TRT4) by 2020, the present study has as problem what information the cost system should generate for TRT4 managers. This research aims to demonstrate the guidelines of the Labor Justice Costing System (SICJT) and the needs for the Regional Labor Court of the Fourth Region Costing System (SICTRT4) pointed by the court managers. This study is defined as qualitative, descriptive and case study. Interviews were conducted with the TRT4 managers and documents related to the SICJT were analyzed. For the SICTRT4 were found: (a) costing method: direct costing method or ABC costing method; (b) apportionment: indirect costs distribution in the judicial and administrative area; (c) benefits: productivity gains, comparability, greater transparency; (d) generated information: judged cases costs from all instances, reports and reliable information; (e) costs centre: 1st and 2nd instances, legal aid, administrative support and autonomous areas. The challenges found are budget, lack of knowledge and disclosure of the system from by the administration, resistance to changes and lack of specific systems.

Keywords: Costing system. Public costing. TRT4. 


\section{INTRODUÇÃO}

A fim de atingir o equilíbrio das contas públicas, obrigatório pela Lei de Responsabilidade Fiscal (LRF), tornou-se necessária uma ferramenta gerencial que auxilie os gestores públicos no processo de tomada de decisão, a exemplo da Contabilidade de Custos. Sob esse âmbito, a contabilidade de custos é uma aliada dos tomadores de decisão para estabelecer quais grupos devem sofrer reduções. Segundo Martins (2010, p. 178), "a Contabilidade de Custos deve não só propiciar as informações gerenciais necessárias para os aspectos decisórios, como auxiliar a Contabilidade Geral na sua tarefa de mensurar os estoques e medir o resultado".

Salienta-se que este controle está previsto na legislação brasileira desde 1964, na Lei no 4.320, mas os gestores não o utilizam por diversos fatores limitativos (BRASIL, 1964). A administração pública necessita da gestão de custos para ter parâmetros e mecanismos que visem à realização do planejamento e à mensuração dos resultados das atividades públicas para amparar as tomadas de decisão, o controle gerencial e a transparência dos serviços (MAUSS; SOUZA, 2008).

Com o limite da implantação de um sistema de custos até 2020, para o Tribunal Regional do Trabalho da 4a Região (TRT4), apresenta-se a seguinte problemática: quais informações o sistema de custos deverá gerar para os gestores do TRT4? A partir dessa problemática, este estudo tem como objetivo geral demonstrar as diretrizes do Sistema de Custos da Justiça do Trabalho (SICJT) e as necessidades do Sistema de Custos do TRT4 (SICTRT4) apontadas pelos gestores do Tribunal, além dos seguintes objetivos específicos:

a) analisar a percepção dos agentes públicos quanto à necessidade de informações e diretrizes do sistema de custos a ser implantado no TRT4;

b) apontar as motivações e dificuldades dos gestores e usuários para a implantação do sistema de custos no TRT4; e

c) identificar o que os gestores públicos e usuários da instituição consideram informações importantes a constar no sistema de custos a ser implantado e os benefícios gerados por ele.

O sistema de gestão de custos aplicado ao setor público permite uma melhor análise dos dispêndios do órgão, o que possibilita aos gestores as tomadas de decisão a respeito de possíveis cortes, a fim de aumentar a economicidade, eficiência e eficácia do mesmo. Com a atual conjuntura econômica do país, a cobrança da prestação de contas pela sociedade e os possíveis cortes orçamentários do Governo Federal, o TRT4 necessita de uma ferramenta para promover cortes em despesas, diminuir os custos processuais e cumprir com as obrigações legais da LRF.

A implantação de um sistema de custos na esfera pública está prevista há décadas, e no TRT4 estava prevista para 2016, contando como prazo o ano de 2020. Essa não se concretizou devido à crise orçamentária. Ao 
realizar um estudo sobre o futuro sistema, será possível apontar os desafios e as diretrizes necessárias aos gestores do tribunal, para vislumbrar seus motivos, intenções e utilidades, possibilitando a verificação de semelhanças e diferenças com o SICJT.

\section{FUNDAMENTAÇÃO TEÓRICA}

Nesta seção são abordados os fundamentos teóricos, baseados na contabilidade de custos aplicada ao setor público, no sistema de custos, nos benefícios dos sistemas de custos nos órgãos públicos e nos estudos relacionados. A subseção 'sistema de custos' é amplamente apresentada, pela relevância das informações desse setor.

\subsection{CONTABILIDADE DE CUSTOS APLICADA AO SETOR PÚBLICO}

De acordo com a International Federation of Accountants (2000), a contabilidade de custos aplicada ao setor público difere daquela do setor privado, uma vez que é utilizada para planejar orçamentos, controlar e reduzir custos, estabelecer preços e taxas, mensurar o desempenho, avaliar programas e tomar inúmeras decisões econômicas. Segundo Mauss e Souza (2008, p. 1), "a gestão pública necessita da contabilidade de custos para the oferecer parâmetros e mecanismos que fundamentam o planejamento e a mensuração do resultado das atividades públicas".

A despesa pública possui três fases dispostas pela legislação: o empenho, a liquidação e o pagamento, sendo o pagamento atrelado à prévia liquidação. Pelo fato de a emissão da nota de empenho não figurar obrigação de pagamento por parte das entidades, as despesas consideradas como custo devem ser apenas as liquidadas, excluindo-se as despesas empenhadas e não liquidadas.

Mauss e Souza (2008, p. 22) afirmam que "[...] pelo fato de o empenho não representar uma obrigação efetiva para o órgão público, o fato gerador do lançamento de custos deve ocorrer na fase da liquidação de empenho". Dessa forma, deve-se apurar para o sistema de custos apenas as despesas liquidadas.

Uma vez que as organizações públicas não vendem serviços, pois não são remuneradas diretamente pelos serviços prestados, estas não têm despesas, apenas custos (MACHADO; HOLANDA, 2010; MAUSS; SOUZA, 2008). Além disso, os custos são atrelados unicamente à produção finalizada do período, logo, não formam estoque. Com a finalidade de se ter um sistema eficiente, é necessário combinar os métodos de custeio com a teoria geral de finanças e avaliar corretamente a relação entre o custo e o benefício gerado (REMÍGIO, 2002). 
Sobre o sistema de acumulação de custos, Mauss e Souza (2008) defendem sua estruturação em três partes:

a) sistema de acumulação de custos: acumula os custos de acordo com o sistema de produção ou execução de serviços;

b) sistema de predeterminação de custos: modelo de mensuração das atividades da gestão; e c)princípios e métodos de custeio: os princípios são os objetivos do sistema, enquanto o método é a técnica utilizada.

\subsection{SISTEMA DE CUSTOS}

O Conselho Federal de Contabilidade (CFC) orienta um sistema de custos aplicado ao setor público por meio do Sistema de Informação de Custos do Setor Público (SICSP), definido pela NBC T 16.11 das Normas Brasileiras de Contabilidade aplicadas ao setor público (NBCASP). Tal ferramenta tem sua eficiência atrelada à integração com o orçamento e o planejamento, obrigatório a todas as entidades.

Com os registros que adotam os princípios contábeis - especialmente o da competência -, que são geradas informações de custos. Elas são posteriormente utilizadas para comparar o custo entre diversas entidades, o que estimula a melhoria do seu desempenho, além de avaliar o desempenho das gestões (CONSELHO FEDERAL DE CONTABILIDADE, 2011).

Salienta-se que são diversas características do sistema que definem seu nível de sofisticação, mas os três aspectos principais da 'sofisticação' do sistema são a sua complexidade, a sua inclusão (alocação) de custos indiretos e sua compreensibilidade pelos usuários não-financeiros (AL-OMIRI; DRURY, 2007; BRIERLEY, 2008; SCHOUTE; BUDDING, 2017). A complexidade, por sua vez, depende da quantidade de centros de custos, da quantidade e da natureza dos direcionadores de custos (BRIERLEY, 2008; DRURY; TAYLES, 2005).

A eficácia dele dependerá da intensidade do uso para diferentes propósitos e da satisfação dos usuários com o sistema (SCHOUTE; BUDDING, 2017). Quanto mais as entidades procuram atender às necessidades de informação dos usuários externos, mais complexo ele será (GEIGER; ITTNER, 1996; LAPSLEY; WRIGHT, 2004; SCHOUTE; BUDDING, 2017).

\subsubsection{Métodos de custeio}

Os métodos de custeio são aqueles utilizados para apropriar os custos aos produtos. "Há vários métodos para atribuir custos e a sua escolha é determinada pela possibilidade de acumulação de custos, disponibilidade 
de informação e pelo próprio método de custeio, o que afeta a precisão da informação" (INTERNATIONAL FEDERATION OF ACCOUNTANTS, 2000, p. 17, tradução dos autores). Estes são alguns métodos de custeio apresentados por Martins (2010):

a) Custeio por Absorção: método derivado da aplicação dos princípios de contabilidade geralmente aceitos. Consiste na apropriação de todos os custos de produção aos bens elaborados, enquanto todos os gastos relativos ao esforço de produção são distribuídos para todos os produtos ou serviços feitos;

b) Custeio Variável ou Direto: consiste na alocação dos custos variáveis aos produtos, onde se separa os custos fixos, que serão considerados como despesas do período, diretamente no Resultado, e se aloca apenas os custos variáveis aos estoques;

c) Custeio Baseado em Atividades (ABC): consiste na captação dos custos dos processos a partir das atividades realizadas nos vários departamentos funcionais; e

d) RKW: consiste no rateio não só dos custos de produção como também de todas as despesas da empresa, inclusive financeiras, a todos os produtos, onde se chega ao custo de 'produzir e vender'.

A escolha do método de custeio varia de acordo com as necessidades, objetivos e limitações da organização. A instituição pode escolher primariamente um método simples de alocação, como o custeio direto, e então aperfeiçoar o método ou o sistema.

\subsubsection{Atributos das informações de custos}

As informações geradas pelo sistema têm algumas propriedades básicas para torná-las úteis. Segundo o Conselho Federal de Contabilidade (2011, p. 6), as informações de custos têm os seguintes atributos:

(a) relevância - entendida como a qualidade que a informação tem de influenciar as decisões de seus usuários auxiliando na avaliação de eventos passados, presentes e futuros;

(b) utilidade - deve ser útil à gestão tendo a sua relação custo benefício sempre positiva;

(c) oportunidade - qualidade de a informação estar disponível no momento adequado à tomada de decisão;

(d) valor social - deve proporcionar maior transparência e evidenciação do uso dos recursos públicos;

(e) fidedignidade - referente à qualidade que a informação tem de estar livre de erros materiais e de juízos prévios, devendo, para esse efeito, apresentar as operações 
e acontecimentos de acordo com sua substância e realidade econômica e, não, meramente com a sua forma legal;

(f) especificidade - informações de custos devem ser elaboradas de acordo com a finalidade específica pretendida pelos usuários;

(g) comparabilidade - entende-se a qualidade que a informação deve ter de registrar as operações e acontecimentos de forma consistente e uniforme, a fim de conseguir comparabilidade entre as distintas instituições com características similares. É fundamental que o custo seja mensurado pelo mesmo critério no tempo e, quando for mudada, esta informação deve constar em nota explicativa;

(h) adaptabilidade - deve permitir o detalhamento das informações em razão das diferentes expectativas e necessidades informacionais das diversas unidades organizacionais e seus respectivos usuários;

(i) granularidade - sistema que deve ser capaz de produzir informações em diferentes níveis de detalhamento, mediante a geração de diferentes relatórios, sem perder o atributo da comparabilidade.

A informação deve ser gerada de acordo com a finalidade do órgão, assim como deve ser relevante para influenciar as decisões dos usuários e precisa apresentar uma relação custo-benefício positiva. Machado e Holanda (2011) determinam que as características qualitativas das informações de custos são: compreensibilidade, tempestividade, comparabilidade, granularidade e confiabilidade, em conformidade com a NBC T 16.11.

Machado e Holanda (2011) ressaltam que a informação deve ter seu benefício gerado superior ao seu custo de obtenção, ser útil e ter valor preditivo, ser oportuna e confiável. Ela precisa apresentar os fatos de forma fidedigna, neutra e verificável e ser comparável entre o tempo, organizações, serviços e objetos de custos comuns.

\subsubsection{Integração do sistema}

O SICSP deve estar integrado aos demais sistemas de informação das entidades do setor público e ao processo de planejamento e orçamento, a fim de permitir o controle entre o orçado e o executado (CONSELHO FEDERAL DE CONTABILIDADE, 2011). A integração de um sistema de informação de custos permite maior eficiência e melhor eficácia do órgão, além de trazer informações com maior veracidade e especificidade. Perottoni et al. (2001, p. 14) afirmam que "a integração elimina a redundância de informação em diferentes sistemas, reduzindo a possibilidade de erros, atrasos e retrabalhos", o que gera informações com menor custo e mais agilidade. 


\subsubsection{Ajustes necessários no sistema}

A informação do Sistema de Custos necessita de ajustes, uma vez que o modelo contábil adotado pelos órgãos públicos utiliza a contabilidade orçamentária. Na contabilidade pública se tem os Restos a Pagar não processados, que são as despesas empenhadas, não liquidadas e não pagas até o dia 31 de dezembro.

Os Restos a Pagar não processados não são considerados como custo. Os Restos a Pagar não processados liquidados no exercício, que são as despesas empenhadas, liquidadas e não pagas até o dia 31 de dezembro, por sua vez, são considerados como custo.

As Despesas de Exercício Anteriores (DEA) se referem às despesas de exercícios encerrados que não tiveram empenhos inscritos em Restos a Pagar por não terem sido empenhadas em época própria, ou cujos empenhos foram anulados ou cancelados.

Quadro 1 - Ajustes no sistema de custos

\begin{tabular}{|l|l|}
\hline Variável Financeira & Informação \\
\hline Contabilidade Orçamentária & Despesa Orçamentária Executada (Despesa Liquidada + Inscrição em RP não-processados) \\
\hline \multirow{5}{*}{ Ajustes Orçamentários } & (-) Despesa Executada por inscrição em RP não-processados \\
\cline { 2 - 2 } & (+) Restos a Pagar Liquidados no Exercício \\
\cline { 2 - 3 } & (-) Despesas de Exercícios Anteriores \\
\cline { 2 - 3 } & (-) Formação de Estoques \\
\cline { 2 - 3 } & (-) Concessão de Adiantamentos \\
\cline { 2 - 3 } & (-) Investimentos/Inversões Financeiras/Amortização da Dívida \\
\hline \multirow{5}{*}{ Ajustes Patrimoniais } & (=) Despesa após ajustes orçamentários \\
\hline & (+) Consumo de Estoque \\
\cline { 2 - 3 } & (+) Despesa Incorrida de Adiantamentos \\
\cline { 2 - 3 } & (+) Depreciação/Exaustão/Amortização \\
\hline \multirow{2}{*}{ Contabilidade Patrimonial } & (=) Despesa após ajustes patrimoniais \\
\hline
\end{tabular}

Fonte: Adaptado de Machado e Holanda (2010) 
Observa-se, no Quadro 1, que, após realizados os ajustes, obtêm-se os custos da entidade. Tais ajustes se dão em decorrência das influências do controle orçamentário em detrimento do controle patrimonial (MACHADO; HOLANDA, 2010).

\subsubsection{Requisitos Funcionais}

Segundo a International Federation of Accountants (2000, p. 30, tradução dos autores) os requisitos funcionais dependem de "[...] como o sistema vai manipular os dados e informações, o que determinará os processos que o sistema vai realizar". A seguir são apontados alguns dos requisitos:

Manter dados no sistema, armazenar dados em outros sistemas, extrair dados de outros sistemas e transferir dados para outros sistemas;

Sumarizar custos classificados para atribuir e calcular custos transferidos a vários objetos de custos atribuídos sob regras armazenadas no sistema;

Associar certas receitas com custos sob outras regras armazenadas no sistema; Calcular custos unitários;

Preparar relatórios e proporcionar suporte ou outros dados no sistema. (INTERNATIONAL FEDERATION OF ACCOUNTANTS, 2000, p. 32-33, tradução dos autores).

Quanto maior a quantidade de informações e requisitos dos relatórios, maior será a complexidade dos requisitos funcionais. A International Federation of Accountants (2000) defende que os relatórios devem fornecer os custos de saídas, precisam ser compreensíveis para o nível acima da gerência operacional e limitados pela essencialidade da informação gerencial. A entidade também aponta que tais documentos devem identificar custos controláveis para cada organização, fornecer detalhes para alertar sobre problemas e comparar os custos com os planejamentos, orçamentos ou padrões, ser consistentes com o regime contábil adotado e relevantes para o planejamento do orçamento e da execução (INTERNATIONAL FEDERATION OF ACCOUNTANTS, 2000).

\subsection{BENEFÍCIOS DOS SISTEMAS DE CUSTOS NOS ÓRGÃOS PÚBLICOS}

O sistema de custos, quando utilizado como ferramenta gerencial, propicia uma gestão mais eficiente, eficaz e econômica. Isso possibilita à organização ter um enfoque gerencial, com auxílio do processo decisório, orçamentário e de planejamento; e promover uma maior transparência das atividades e dos gastos da organização. No Quadro 2, apresenta-se as utilidades das informações dos sistemas de custos, segundo diversos autores: 


\section{Quadro 2 - Utilidade das informações dos Sistemas de Custos}

\begin{tabular}{|c|c|}
\hline Autor (es) & Principais utilidades das informações \\
\hline Machado e Holanda (2010) & $\begin{array}{l}\text { Definir políticas públicas; cumprir com eficiência, eficácia e efetividade as políticas } \\
\text { públicas; comparar unidades organizacionais diferentes; formular propostas orçamentárias } \\
\text { e de planejamento; fixar preços públicos e taxas; subsidiar alocações mais eficientes e } \\
\text { aumentar a transparência dos processos. }\end{array}$ \\
\hline Verbeeten (2011) & $\begin{array}{l}\text { Reduzir custos; melhorar a economicidade, eficiência e a alocação de recursos; calcular } \\
\text { custo dos produtos, serviços e outros objetos; subsidiar informação para planejamento, } \\
\text { controle e avaliação de desempenho; formular estratégias, planos e orçamentos; formar } \\
\text { preços e valores de estoque; preparar análises para privatizações; legitimar as atividades da } \\
\text { organização; satisfazer a legislação. }\end{array}$ \\
\hline Honda (2011) & $\begin{array}{l}\text { Avaliar ações; melhorar e avaliar a eficiência, eficácia, efetividade, qualidade e } \\
\text { transparência; reduzir desperdícios; aprimorar os produtos e a gestão pública. }\end{array}$ \\
\hline Cardoso, Aquino e Bitti (2011) & $\begin{array}{l}\text { Comparar desempenho de bens, serviços, postos de operação; avaliar desempenho de } \\
\text { equipes, decidir preços e taxas, elaborar proposta orçamentária, decidir a redução do nível } \\
\text { de atividades contingenciadas, avaliar cláusulas de contratos da gestão e alcance de metas. }\end{array}$ \\
\hline $\begin{array}{l}\text { Conselho Federal de } \\
\text { Contabilidade (2011) }\end{array}$ & $\begin{array}{l}\text { Mensurar, registrar e evidenciar os custos dos produtos, serviços, programas, projetos, } \\
\text { atividades, ações, órgãos e outros objetos de custos das entidades; apoiar a avaliação } \\
\text { de resultados e desempenhos; comparar entidades; apoiar a tomada de decisão; apoiar } \\
\text { o planejamento e o orçamento; apoiar programas de redução de custos e melhoria da } \\
\text { qualidade dos gastos. }\end{array}$ \\
\hline Souza e Carvalho (2012) & $\begin{array}{l}\text { Controle dos gastos pela sociedade; aumentar a transparência; subsidiar as decisões } \\
\text { dos gestores; estudar a viabilidade econômica; avaliar a eficiência, eficácia, efetividade e } \\
\text { economicidade. }\end{array}$ \\
\hline Gosselin, Henri e Laurin (2015) & $\begin{array}{l}\text { Mensurar o custo dos produtos/serviços; justificar o aumento de taxas; legitimar a } \\
\text { existência da organização. }\end{array}$ \\
\hline Lorenzato, Behr e Goularte (2016) & $\begin{array}{l}\text { Apontar atrasos na legislação e na estrutura prática dos órgãos; organizar a vida dos } \\
\text { servidores; identificar os gastos individuais; medir eficiência; aumentar a efetividade e a } \\
\text { qualidade dos gastos. }\end{array}$ \\
\hline
\end{tabular}

\section{Fonte: Elaborado a partir de diversos autores (2017)}

É fato que o sistema de custos gera uma gama de informações, tanto ao controle social quanto ao processo de tomada de decisão. Tal ferramenta, se implantada e integrada adequadamente, auxilia a organização a tomar decisões mais econômicas e fundamentadas. Da mesma forma, permite a definição de preços públicos e taxas, o controle do gasto público pela sociedade, a avaliação do desempenho de programas, projetos, ações e gestores, bem como a comparação entre os órgãos da administração pública. 


\subsection{ESTUDOS RELACIONADOS}

A contabilidade de custos aplicada ao setor público tem apresentado nos últimos anos uma variedade de trabalhos científicos, uma vez que tem uma crescente adesão pelas entidades. Entre os autores, pode-se citar Machado (2002), Verbeeten (2011), Honda (2011), Santos (2014), Gosselin, Henri e Laurin (2015) e Lovato (2015).

O trabalho realizado por Machado (2002) propõe diretrizes para a construção de um sistema de custos integrado, conceitual sistematicamente ao orçamento público e à contabilidade governamental, além de analisar o sistema de informação do Estado de São Paulo com vistas a sua implantação. Foi realizada uma pesquisa empírica de caráter exploratório com questionário e revisão bibliográfica. Os resultados alcançados apontam a existência de uma integração entre o sistema de informação do Estado de São Paulo, a contabilidade governamental e o sistema orçamentário, bem como a compreensão dos gestores sobre a importância do sistema de custos em sua tomada de decisão.

Em linha semelhante, o artigo elaborado por Verbeeten (2011) buscou validar a afirmação de que os recentes desenvolvimentos no âmbito público aumentaram a demanda do uso da gestão de custos nas organizações do setor, e teve como procedimento o survey realizado com os gestores financeiros nas organizações públicas da Holanda. Os principais resultados apontam que a concepção e o uso de sistemas de gestão de custos diferem de acordo com as entidades e sugerem que as informações dos sistemas de gestão de custos são usadas mais para legitimar as atividades das organizações para os stakeholders externos do que para gerir as instituições. Isso desafia a afirmação de que as informações gerenciais de custos se tornaram importantes na gestão das organizações do setor público.

Em 2011, Honda publicou um artigo para avaliar a influência do Sistema de Custos na tomada de decisão do gestor público, a fim de aperfeiçoar a qualidade dos gastos públicos e revisar as principais teorias e postulados relacionados à eficiência dos recursos públicos, à demonstração da importância de um Sistema de Custos na Administração Pública e à exposição de casos práticos. A pesquisa de caráter descritivo e exploratório, com o meio de revisão bibliográfica, indicou a ausência de cultura gerencial de custos no setor público. Entretanto, apontou que a imposição da legislação e a mudança de paradigma favorecem a criação de tais sistemas na busca qualitativa e quantitativa pela eficiência dos recursos.

É importante destacar o estudo de Santos (2014), que propôs diretrizes para implantação de um Subsistema de Mensuração e Acumulação de Informação de Custos no Setor Público (SMAIC-SP), integrado aos princípios da Contabilidade e às Normas Brasileiras de Contabilidade aplicadas ao setor público, em especial à NBC TSP 
16.11 - Sistema de Informação de Custos no Setor Público. A metodologia aplicada foi a pesquisa dedutiva, com abordagem qualitativa e técnica de pesquisa bibliográfica. Como resultado, é apontado que a estrutura proposta do sistema pode auxiliar no processo de identificação dos custos dos serviços públicos por objeto de custo. Esse sistema contribui para o processo de prestação de contas, tomada de decisão e instrumentalização do controle social e, por conseguinte, auxilia as entidades públicas nos processos de implantação do SICSP.

Já Gosselin, Henri e Laurin (2015) avaliaram o impacto na perspectiva da consciência de custos com a reforma do setor público utilizando a Nova Gestão Pública (NGP). Foi realizada uma pesquisa-ação, onde foi examinada qual intensidade de pressão externa influencia a lógica institucional na qual as organizações do setor público geram seus custos. O estudo apontou que, mesmo após a descentralização, as organizações do setor público parecem incapazes de mover a finalidade de custeamento de controle de despesas para gerência de custos, a menos que pressões externas motivem os gerentes a completar a reforma. A partir disso, percebeu-se maior possibilidade de sucesso da reforma do sistema quando as organizações sofrem fortes pressões, tanto com incentivo quanto com ameaças externas.

Destaca-se o estudo de Lovato (2015), que discutiu a percepção dos usuários sobre a importância do SICSP para a gestão e desenvolvimento municipal, por meio de um questionário, analisando de forma univariada e com o auxílio do teste qui-quadrado e de forma bivariada. Ainda que o prazo legal de implantação tivesse terminado, grande parte dos respondentes não havia concluído o processo, apesar do entendimento de que o SICSP contribui significantemente para a gestão e desenvolvimento do município. O sistema de custos possibilitaria, entre outros, apontar carência de pessoal qualificado tecnicamente para a implantação e utilização do SICSP e a insuficiência do quantitativo de pessoal em muitos dos casos pesquisados.

\section{PROCEDIMENTOS METOdOLÓGICOS}

O presente estudo é abordado de forma qualitativa, tendo em vista que foram realizadas entrevistas com os servidores. Richardson (1999) ressalta que a abordagem qualitativa "[...] pode descrever a complexidade de determinado problema, analisar a interação de certas variáveis e classificar e compreender processos dinâmicos vividos por grupos sociais", haja vista que "na pesquisa qualitativa concebem-se análises mais profundas em relação ao fenômeno que está sendo estudado" (RAUPP; BEUREN, 2013, p. 92).

Quanto aos objetivos, é uma pesquisa descritiva. Gil (2009, p. 28) destaca que as pesquisas descritivas “[...] têm como objetivo primordial descrever características de determinada população ou fenômeno ou o estabelecimento de relações entre as variáveis". O procedimento técnico utilizado foi o estudo de caso, que 
"[...] é caracterizado pelo estudo profundo e exaustivo de um ou de poucos objetos, de maneira a permitir o seu conhecimento amplo e detalhado" (GIL, 2009, p. 57-58). Tal estudo de caso foi possível pela triangulação de procedimentos, sendo: entrevista, observação in loco e análise documental.

O estudo tem como área o Tribunal Regional da 4a Região, cuja sede está localizada na Av. Praia de Belas, 1.100, em Porto Alegre, Rio Grande do Sul. O tribunal dispõe, na primeira instância, de 132 Varas do Trabalho e 10 Postos Avançados, localizados em 65 municípios, com jurisdição sobre uma ou mais cidades, abrangendo todos os municípios gaúchos, enquanto na segunda instância dispõe de 48 desembargadores e 11 Turmas Julgadoras (TRIBUNAL REGIONAL DO TRABALHO DA 4a REGIÃO, 2016).

A coleta de dados se deu no período de janeiro a abril de 2017, utilizando-se uma entrevista semiestruturada realizada com quatro gestores: um analista judiciário; dois analistas contadores; e um analista economista do tribunal. A partir das entrevistas (Roteiro no Quadro 3), foi realizada uma análise qualitativa para relacionar as usabilidades, as motivações e as informações relevantes.

\section{Quadro 3 - Roteiro de entrevistas}

(continua)

1 - Você concorda que há uma nova cultura na sociedade quanto à evidenciação pública de informações gerenciais de custos?

2 - Em sua opinião, para os órgãos controladores e para a sociedade civil em geral, a percepção do sistema de custos é em relação ao sistema em si ou ao uso das informações geradas?

3 - Em sua opinião, será importante implantar um sistema de custos no Tribunal? A informação gerada por tal sistema seria útil?

4 - No tribunal, a informação gerada pelo sistema de acumulação de custos seria utilizada para decisões gerenciais?

5 - Já ocorre algum tipo de controle de custos na entidade? De que forma?

6 - Pela NBC TA 16.11 a análise, avaliação e a verificação da consistência das informações de custos são de responsabilidade do gestor da entidade do setor público. No TRT qual seria o setor/cargo responsável?

7 - Em sua opinião, quais fatores dificultam a implantação do sistema de custos no TRT?

8 - No seu entender, qual seria a estratégia de implantação do sistema de custos?

9 - O Conselho Superior da Justiça do Trabalho criou um grupo para modelar o sistema de custos da Justiça do Trabalho. Tu acreditas que este sistema deve ser padronizado, a fim de ter uma maior comparabilidade da informação, ou deve atender a especificidade de cada órgão, tendo diretrizes diferentes?

10 - Como o Sr. entende que o Sistema de custos, a ser implantado, deverá capturar informações dos demais sistemas das entidades do setor público? Com quais sistemas este será integrado?

11 - Em sua opinião, qual seria um bom modelo de alocação de custos indiretos? Qual seria o método de custeio utilizado e quais os principais centros de custos a entidade terá? 


\begin{abstract}
12 - Na NBC TA 16.11 a responsabilidade pela consistência conceitual e apresentação das informações contábeis do sistema de custos é do profissional contábil. Em sua opinião, quais seriam os principais conceitos e como devem ser apresentadas tais informações de custos?
\end{abstract}

13 - Você acredita que há disponibilidade orçamentária e previsão no Planejamento Estratégico do Órgão para implantar o sistema de custos?

14 - Você acredita que há interesse da administração para implantação do sistema? Por quê?

15 - O que vem sendo feito desde 2004 para viabilizar a implantação de um sistema de custos no TRT4?

16 - Quais os empecilhos encontrados, que mais postergaram essa implantação?

17 - O acórdão no 1.078/2004 do Tribunal de Contas da União determina a adoção de providências para que a administração pública federal possa dispor com a maior brevidade possível de sistema de custos. Quanto ao TRT, quando este será implantado?

18 - Quais informações o sistema deverá gerar para os usuários?

\title{
Fonte: Elaboração própria (2017)
}

Foi realizado o pré-teste do roteiro de entrevistas com quatro profissionais, sendo três professores especialistas em contabilidade pública, vinculados à UFRGS, e uma encarregada do sistema de custos da Contadoria e Auditoria Geral do Estado do Rio Grande do Sul. Assim, para a elaboração e adequação do roteiro de entrevista, considerou-se a literatura sobre o tema e tais informações obtidas no pré-teste para aperfeiçoamento da estrutura e para a clareza do roteiro.

\section{RESULTADOS E ANÁLISE}

Nesta seção são analisados os dados obtidos nas entrevistas e na análise documental, evidenciando, primeiramente, as premissas do sistema de custos, as percepções dos agentes públicos com relação às informações necessárias, suas diretrizes principais para o TRT4, finalizando com as motivações e dificuldades para a implantação do sistema.

\subsection{SISTEMA DE CUSTOS DA JUSTIÇA DO TRABALHO}

O Conselho Superior da Justiça do Trabalho (CSJT) começou a realizar estudos técnicos para desenvolver o Sistema de Custos da Justiça do Trabalho em 2013, com o ato no 398, de 29 de outubro de 2013. O Sistema de Informação de Custos da Justiça do Trabalho teve sua primeira implantação no Tribunal Superior do Trabalho (TST), onde foi criado o SICTST, que já está em funcionamento. O ano limite para implantação do 
sistema nos Regionais é 2020, sendo ela estruturada em quatro fases: preparatória; modelagem; projetos pilotos e aperfeiçoamento; e implantação. Atualmente, encontra-se na quarta etapa. Cancio (2014, p. 13-14) aponta as seguintes premissas básicas do sistema:
I. Foco no custo do processo julgado;
II. Segregação dos custos da $1^{\text {a }}$ (Varas do Trabalho) e 2a (TRTs) instâncias;
III. Agregação de valor ao processo decisório, ao oferecendo relatórios gerenciais;
IV. Utilização do método de Custeio Direto;
V. Segregação dos custos indiretos sem rateio em centros de custos específicos;
VI. Departamentalização em centro de custos específicos, agrupando as unidades administrativas das áreas meio e finalística;
VII. Utilização de centros de custos cadastrados no SIAFI;
VIII. Utilização da aba do CPR (Detacustos) para alocação dos custos identificados;
IX. [...]
$X .[\ldots]$
XI. Geração de relatórios padronizados de custo a partir do SIC;
XII. Desenvolvimento do Sistema Unificado de Custos da JT;
XIV. Desenvolvimento de ferramentas de TI compatíveis ao SIC e adequadas;

O SICJT utiliza a ferramenta Business Objects (BO) da SAP, tendo um Data Warehouse (DW), o qual provê uma base de dados à parte, com o processo ETL (Extração, Transformação e Load/Carga), que extrai dados do sistema de origem, trata e carrega à base, o que permite visualizar os dados (CANCIO, 2014). As vantagens deste sistema são a preservação de histórico de dados, obtenção de dados de diversas origens, possibilidade de cruzamentos, tempo de execução baixo e possibilidade de geração de relatórios e consultas sem necessidade de conhecimento tecnológico avançado (CANCIO, 2014).

A International Federation of Accountants (2010, p. 30, tradução dos autores) aponta requisitos funcionais do sistema, entre estes está "[...] manter dados no sistema, armazenar dados em outros sistemas, extrair dados de outros sistemas e transferir dados para outros sistemas", o que é possível com a ferramenta DW. Machado e Holanda (2010, p. 21) afirmam sobre o método de custeio direto que "[...] por não conter qualquer tipo de rateio, permite analisar o desempenho dos gestores e das políticas públicas com maior objetividade e sem as intermináveis discussões a respeito dos custos gerais transferidos".

De acordo com Cancio (2014), os desafios apontados para a implantação do sistema são:
a) sensibilizar a administração, gestores e operadores;
b) disseminar a cultura de custos nos tribunais; 

c) desenvolver solução de TI padronizada e compatível com o SIC;
d) criar a Setorial de Custos da Justiça do Trabalho;
e) criar estrutura de custos nos tribunais;
f) padronizar os sistemas estruturantes nos tribunais;
g) implantar um sistema de custos único para a Justiça do Trabalho;
h) treinar e capacitar os operadores do SIC; e
i) incentivar o uso de informações de custos no processo decisório.

A partir da visualização de tais desafios, observa-se que é necessário o envolvimento dos gestores dos Tribunais Regionais para que o processo de implantação seja realizado, com investimentos monetários e de recursos humanos.

\title{
4.2 ANÁLISE DA PERCEPÇÃO DOS AGENTES PÚBLICOS QUANTO ÀS NECESSIDADES DE INFORMAÇÕES
}

A eficiência, a eficácia e a economicidade dos órgãos públicos têm sido cada vez mais exigidas pelos órgãos controladores (internos e externos) e pela sociedade, por meio do controle social. Honda (2011, p. 4) aponta que "a promoção da transparência governamental é condição necessária à modernização dos mecanismos de gestão governamental, à promoção de melhoria na qualidade dos gastos públicos e à consolidação da democracia" e que governos mais transparentes são melhores e mais eficientes e têm menor dispêndio de recursos e melhor funcionamento (HONDA, 2011).

Os gestores acreditam que, pelo caráter extremamente técnico da prestação de contas, muitas vezes se conclui precipitadamente sobre o gasto e o benefício gerados pelo governo, e que, ao incluir informações menos técnicas, ter-se-á mais interesse por parte do controle social sobre os gastos no setor público.

\begin{abstract}
Atualmente a prestação de contas é muito técnica, apresenta diversas classificações orçamentárias e valores relativos à execução que não estão acessíveis a pessoas que não tenham um profundo conhecimento de orçamento público. Entendo que a dissociação do orçamento público e do patrimônio público trazidos pelas Normas Brasileiras de Contabilidade Aplicada ao Setor Público irá propiciar um entendimento melhor da prestação de contas para os órgãos de controle bem como para sociedade (ENTREVISTADO A).
\end{abstract}

O entrevistado B aponta que os órgãos controladores e alguns setores da sociedade exigem informações cada vez mais detalhadas dos serviços e das despesas públicas, o que torna a inclusão de informações gerenciais 
de custos uma consequência natural deste processo. As informações geradas pelo sistema teriam um caráter menos técnico e possibilitariam uma melhor análise por parte dos usuários com menor conhecimento técnico, além de criar informações mais fidedignas. Os relatórios gerados possibilitariam uma melhor análise dos resultados dos programas, das ações, das atividades e das decisões dos gestores.

\subsection{ANÁLISE DAS DIRETRIZES DO SISTEMA DE CUSTOS A SER IMPLANTADO NO TRT4}

O Entrevistado B salienta que o planejamento da implantação do sistema seguirá as mesmas fases do SICTST e que ela está bem estruturada. Ele também aponta que, por regra, a responsabilidade da implantação é do Presidente da entidade, embora ela possa ser delegada ao Diretor-Geral, ao Secretário de Administração ou ao Coordenador de Contabilidade. O Conselho Federal de Contabilidade (2011, p. 7) aponta as seguintes questões que devem ser consideradas no processo de implantação:

O processo de implantação do SICSP deve ser sistemático e gradual e levar em consideração os objetivos organizacionais pretendidos, os processos decisórios que usarão as informações de custos segmentados por seus diferentes grupos de usuários, bem como os critérios de transparência e controle social.

O Entrevistado A entende que, tanto a implantação quanto a análise, a gestão e a melhoria contínua do sistema deveriam ser responsabilidade da Coordenadoria de Contabilidade, representada pelo Coordenador de Contabilidade, que deve ser graduado em Ciências Contábeis e ter qualificação e conhecimento técnico necessário para gerar informações úteis. O Conselho Federal de Contabilidade (2011, p. 9) afirma que "[...] a responsabilidade pela consistência conceitual e apresentação das informações contábeis do subsistema de custos é do profissional contábil". Nessa norma é definido que o sistema de custos deve estar integrado com o processo de planejamento e orçamento e utilizar a mesma base conceitual, o que permite controlar o que foi orçado e o que foi executado (CONSELHO FEDERAL DE CONTABILIDADE, 2011).

Para permitir a comparabilidade das informações o sistema deve ser padronizado. Devido às similaridades entre os Tribunais, a padronização será viável e, segundo o Entrevistado A, permitirá que as informações geradas sejam harmônicas e consolidadas. Os gestores acreditam que o mesmo será integrado ao Sistema Integrado de Administração Financeira do Governo Federal (SIAFI), ao Sistema e-Gestão e aos sistemas de Compras, Almoxarifado, Patrimônio e Folha de Pagamento, e alimentar-se-á com os respectivos dados.

Como o sistema tende a ser padronizado, e que haverá um controle centralizado sobre as informações, a responsabilidade pela consistência conceitual não será exclusivamente do contador da unidade, mas compartilhada com o responsável 
pela contabilidade do órgão setorial. Entendo que os sistemas atuais dos diversos Tribunais não estarão preparados para se comunicar com o sistema de Custos, exigindo que da implantação, também haja a padronização dos diversos sistemas estruturantes, como da execução orçamentária e financeira, almoxarifado, patrimônio e folha de pagamento, permitindo assim a elaboração da mesma base conceitual para a efetiva integração ao sistema de Custos (ENTREVISTADO A).

A padronização do sistema de custos e dos sistemas integrados é necessária para que as informações sejam comparáveis. Apesar da padronização, há uma enorme disparidade entre as despesas correntes e de investimento dos órgãos, o que pode gerar discrepâncias na informação final (ENTREVISTADO C). Souza e Carvalho (2012, p. 15) afirmam que se tem "[...] necessidade de investimentos em softwares e hardwares, sistema específico de custos, e maior formação do pessoal técnico em contabilidade” para o sistema funcionar.

Beulke e Bertó (2005) defendem que as criações de centros de custos obedecem aos princípios de homogeneidade funcional (ter escopo homogêneo à sua função), locais físicos semelhantes e unidade de responsabilidade (equivalência entre o centro de custos e o organograma do órgão). Já Mauss e Souza (2008, p. 67) apontam as seguintes vantagens do método de custeio ABC:

$\mathrm{O}$ ABC consegue um rastreamento racional de custos, identificando suas atividades geradoras, coletando para cada departamento ou centro de custos todos os custos que podem ser atribuídos a eles, independentemente de serem fixos ou variáveis. Dessa forma, pode ser considerado uma técnica de absorção de custos indiretos muito criteriosa, acurada e menos arbitrária que as técnicas do método por absorção tradicional.

Os centros de custos seriam divididos nas duas áreas do Tribunal, a Área Judiciária, composta pelo $1^{\circ}$ e 20 Grau e a Área Administrativa, que realiza as atividades de apoio para a prestação dos serviços da Área Judiciária. O Entrevistado B defende a seguinte estruturação dos centros de custos:

Os centros de custos poderiam ser divididos nos seguintes grupos (1) Unidades do $1^{\circ}$ Grau (varas do trabalho), (2) Unidades do $2^{\circ}$ grau (turmas do TRT); (3) Apoio Judiciário (secretarias, coordenadorias e seções) (4) Apoio Administrativo (secretarias, coordenadorias e seções), (5) Áreas autônomas (Escola Judicial).

Os entrevistados apontaram diferentes métodos de custeio, como o custeio baseado em atividades (ABC) e o custeio direto. O método utilizado no sistema já implantado no TST é o direto. O método de rateio 
utilizado para alocar os custos indiretos na área judiciária seria o número de processos julgados e, na área administrativa, a quantidade de servidores lotados na seção (ENTREVISTADO A).

\subsection{MOTIVAÇÕES E DIFICULDADES DOS GESTORES E USUÁRIOS PARA A IMPLANTAÇÃO DO SISTEMA DE CUSTOS NO TRT}

Todos os gestores entrevistados consideram importante a implantação do sistema no órgão, por diversas razões. Em 2016, foi aprovada a Emenda Constitucional 95, que instituiu o Novo Regime Fiscal, que congelou por vinte exercícios financeiros as despesas primárias (BRASIL, 2016). Sem flexibilidade nos orçamentos futuros, será necessária uma ferramenta que possibilite a apuração e a futura análise de informações sobre possíveis áreas de investimento e sobre volume e cortes de gastos, o que auxiliará a tomada de decisão por parte dos gestores. Ao utilizar informações mais fidedignas e mais amplas, ter-se-ia mais transparência, melhor avaliação da eficiência e da eficácia dos gastos públicos e a melhoria dos serviços prestados.

Sem dúvida, um sistema de custos é importante na medida em pode fornecer informações gerenciais úteis para o planejamento e tomadas de decisão dos gestores do Tribunal. É uma ferramenta que permite avaliar se a alocação de recursos é adequada e compará-la ao longo do tempo. Com a aprovação da Emenda Constitucional 95/2016 que restringe por 20 anos o total da despesa dos órgãos públicos, ferramentas que permitam a economia e a racionalização dos recursos orçamentários ganham importância. Para os usuários externo, o sistema de custos pode ser útil para melhorar a avaliação e o controle da eficiência e eficácia dos gastos públicos. (ENTREVISTADO B).

O CSJT incluiu no objetivo estratégico da Justiça do Trabalho do período de 2015-2020 a perspectiva de 'aperfeiçoar a gestão de custos', referente à:

[...] utilização de mecanismos para alinhar as necessidades orçamentárias, de custeio, investimentos e pessoal ao aprimoramento da prestação jurisdicional, atendendo aos princípios constitucionais da administração pública. Envolve estabelecer uma cultura de redução do desperdício de recursos públicos (BRASIL, 2014).

Tal objetivo foi absorvido pelo Plano Estratégico do TRT4, o que demonstra o interesse da melhor gestão dos custos, auxiliada pelo sistema (TRIBUNAL REGIONAL DO TRABALHO DA 4a REGIÃO, 2015).

A principal dificuldade para proceder à implantação do sistema é orçamentária. Esse problema teve início em 2016, com um acentuado corte na Justiça do Trabalho. Em 2017, com o congelamento do orçamento, 
persistiram as restrições e as incertezas orçamentárias, o que fez com que o projeto não avançasse, apesar de suas vantagens. Ademais, o Entrevistado A acredita que a administração não tem pleno conhecimento dos benefícios e vantagens gerados pelo sistema, enquanto o Entrevistado $\mathrm{C}$ pensa que a falta de divulgação destas informações posterga ainda mais o processo.

O Entrevistado C aponta que, de modo geral, os seres humanos têm resistência a novidades que os façam sair da sua zona de conforto e aumentar suas atividades, o que obrigaria a criação de uma unidade exclusiva para o gerenciamento de custos. As pessoas apresentam resistência à implementação de sistemas de informação pela possibilidade de mudança do seu status quo e de seu poder (JOIA; MAGALHÃES, 2009; KIM; KANKANHALLI, 2009; LAPOINTE; RIVARD, 2005).

Sob esse ponto, Lapsley e Wright (2004, p. 18, tradução dos autores) apontam que "inovações contábeis se originam principalmente no setor privado, e que a adoção destas inovações pelas organizações do setor público é amplamente atribuída pela influência governamental”. A chamada influência governamental é exercida por lei, regulamentação ou pressão estatal. Gosselin, Henri e Laurin (2015, p. 18, tradução dos autores) demonstram que "sem pressões externas e incentivos, organizações do setor público parecem ter dificuldades para coexistir com duas funções de custos, o controle de despesas e o gerenciamento de custos, mesmo com a Nova Gestão Pública (NGP)".

\subsection{INFORMAÇÕES A CONSTAR NO SISTEMA DE CUSTOS A SER IMPLANTADO E OS BENEFÍCIOS GERADOS}

O sistema deverá gerar o custo de cada processo julgado, segregado pelas instâncias (primeira e segunda), além de relatórios, que demonstram os custos relativos a mão de obra, depreciação de imóveis, aluguel de imóveis, energia elétrica, consumo de materiais do almoxarifado e despesas com serviços continuados. Esses custos são alocados às Varas do Trabalho, aos Gabinetes, às Secretarias, aos Dissídios, à Presidência, à Escola Judicial e à Área Administrativa. Tais informações devem permitir gerar ganhos de produtividade, verificar quais unidades trabalham fora do padrão, comparar as unidades internas e externas e apontar o custo médio do processo trabalhista, por unidade e pelos graus de jurisdição (ENTREVISTADO B).

A distribuição dos recursos entre o primeiro e o segundo graus de jurisdição será uma das informações do sistema, haja vista a exigência do CNJ. Os relatórios permitirão a minimização e gerenciamento dos gastos públicos e apontará o custo para produzir os imóveis no local, o que permitirá a verificação da viabilidade da produção de imóveis e sua correta mensuração. Alguns dos benefícios gerados pelo sistema são a comparabilidade das unidades organizacionais (CARDOSO; AQUINO; BITTI, 2011; MACHADO; HOLANDA, 
2010), aprimoramento da gestão pública (HONDA, 2011), evidenciação dos custos dos produtos e serviços (VERBEETEN, 2011; CONSELHO FEDERAL DE CONTABILIDADE, 2011; GOSSELIN; HENRI; LAURIN, 2015) e formulação de orçamentos e planejamento (CARDOSO; AQUINO; BITTI, 2011; CONSELHO FEDERAL DE CONTABILIDADE, 2011; INTERNATIONAL FEDERATION OF ACCOUNTANTS, 2010; MACHADO; HOLANDA, 2010; VERBEETEN, 2011). O sistema gera informações que permitem alocações mais eficientes, melhora o desempenho e a qualidade dos gastos das organizações e cumpre com as exigências legais da eficiência, eficácia e efetividade (CONSELHO FEDERAL DE CONTABILIDADE, 2011; HONDA, 2011; LORENZATO; BEHR; GOULARTE, 2016; MACHADO; HOLANDA, 2010)

No Quadro 4 é apresentada a comparação entre o sistema desenhado para a Justiça do Trabalho e o sistema idealizado para o TRT4, a partir das necessidades apontadas pelos gestores:

\section{Quadro 4 - comparação entre o SICJT e SIC TRT4}

\begin{tabular}{|c|c|c|}
\hline Quesito & SICJT & SIC TRT4 \\
\hline $\begin{array}{l}\text { Fases de } \\
\text { implantação }\end{array}$ & $\begin{array}{l}\text { Fase preparatória, modelagem, projetos pilotos e } \\
\text { aperfeiçoamento e implantação. }\end{array}$ & $\begin{array}{l}\text { Fase preparatória, modelagem, projetos } \\
\text { pilotos e aperfeiçoamento e implantação. }\end{array}$ \\
\hline Método de custeio & Custeio Direto. & Custeio Direto e ABC. \\
\hline $\begin{array}{l}\text { Alocação de } \\
\text { custos indiretos }\end{array}$ & São alocados a um centro de custos, separadamente. & $\begin{array}{l}\text { Rateio com base no número de processos } \\
\text { julgados (área judiciária) e com base na } \\
\text { quantidade de pessoal (área administrativa). }\end{array}$ \\
\hline $\begin{array}{l}\text { Dificuldades de } \\
\text { implantação }\end{array}$ & $\begin{array}{l}\text { Sensibilizar a administração, gestores e operadores; } \\
\text { disseminar a cultura de custos nos tribunais; } \\
\text { desenvolver solução de TI padronizada e compatível } \\
\text { com o SIC; criar a Setorial de Custos da Justiça do } \\
\text { Trabalho; criar estrutura de custos nos tribunais, } \\
\text { padronizar os sistemas estruturantes nos tribunais; } \\
\text { implantar um sistema de custos único para a Justiça } \\
\text { do Trabalho; treinar e capacitar os operadores do SIC; } \\
\text { incentivar o uso de informações de custos no processo } \\
\text { decisório. }\end{array}$ & $\begin{array}{l}\text { Restrições e incertezas orçamentárias; falta } \\
\text { de conhecimento dos benefícios e vantagens } \\
\text { gerados pelo sistema; falta de divulgação } \\
\text { do sistema; aversão a novidades; medo dos } \\
\text { funcionários quanto ao aumento das suas } \\
\text { atividades e fim da sua "zona de conforto"; } \\
\text { falta de sistemas específicos. }\end{array}$ \\
\hline Benefícios & $\begin{array}{l}\text { Preservação de histórico de dados; obtenção de dados } \\
\text { de diversas origens e possibilidade de cruzamentos; } \\
\text { tempo de execução baixo e possibilidade de geração de } \\
\text { relatórios; consultas sem necessidade de conhecimento } \\
\text { tecnológico avançado. }\end{array}$ & $\begin{array}{l}\text { Ganhos de produtividade; comparação } \\
\text { entre as unidades internas e externas; } \\
\text { verificação dos padrões das unidades; maior } \\
\text { transparência; melhor avaliação dos gestores } \\
\text { públicos. }\end{array}$ \\
\hline
\end{tabular}


(conclusão)

\begin{tabular}{|l|l|l|}
\hline Quesito & SICJT & SIC TRT4 \\
\hline $\begin{array}{l}\text { Informações } \\
\text { geradas }\end{array}$ & $\begin{array}{l}\text { Custo do processo julgado; segregação dos custos das } \\
1^{\text {a }(V a r a s ~ d o ~ T r a b a l h o) ~ e ~ 2 a ~(T R T) ~ i n s t a ̂ n c i a s ; ~ r e l a t o ́ r i o s ~} \\
\text { padronizados. }\end{array}$ & $\begin{array}{l}\text { Custo do processo julgado pelas instâncias; } \\
\text { relatórios demonstrando custos relativos } \\
\text { à mão-de-obra, depreciação de imóveis, } \\
\text { aluguel de imóveis, energia elétrica, consumo } \\
\text { de materiais do almoxarifado e despesas com } \\
\text { serviços continuados; informações sobre as } \\
\text { unidades internas e seus padrões; custo para } \\
\text { produção de imóveis; informações confiáveis. }\end{array}$ \\
\hline Centros de custos & $\begin{array}{l}\text { Departamentalização em centros de custos específicos, } \\
\text { agrupando as unidades administrativas das áreas meio } \\
\text { e finalísticas. }\end{array}$ & $\begin{array}{l}\text { Unidades do 10 Grau (Varas do Trabalho); } \\
\text { Unidades do 20 Grau (turmas do TRT); Apoio } \\
\text { Judiciário (secretarias, coordenadorias e } \\
\text { seções); Apoio Administrativo (secretarias, } \\
\text { coordenadorias e seções); Áreas Autônomas } \\
\text { (Escola Judicial). }\end{array}$ \\
\hline
\end{tabular}

\section{Fonte: Elaboração própria (2017)}

É possível se verificar, no Quadro 4, as diferenças entre os sistemas, tendo em vista que o SICJT foi pensado para todos os órgãos da Justiça do Trabalho, enquanto o sistema idealizado pelos gestores do TRT4 procura atender às especificidades desta entidade. Para que o sistema possa ser padronizado, será necessário investir em ferramentas de Tecnologia da Informação (TI) específicas e padronizar as áreas judiciárias e administrativas de todos os órgãos, tendo como principais dificuldades as questões orçamentárias e de recursos humanos.

\section{CONSIDERAÇÕES FINAIS}

O presente estudo objetivou demonstrar os desafios para a implantação do Sistema de Custos do TRT4 apontadas pelos gestores do Tribunal e diretrizes do SICJT. Para este fim, foram realizadas entrevistas com os gestores do TRT4 e uma pesquisa documental, a partir das premissas básicas do sistema de informação de custos da Justiça do Trabalho.

Observou-se que, no SICJT, o método de custeio utilizado é o Custeio Direto, com departamentalização de centros de custos específicos, que agrupam as unidades administrativas das áreas meio e fim, com seus Custos Indiretos alocados a um centro de custos separado. As dificuldades encontradas se referem à sensibilização da administração dos Regionais, à criação e implantação de um Sistema de Custos único para 
a Justiça do Trabalho - junto de soluções de TI padronizadas e compatíveis com o SIC -, ao treinamento e à capacitação dos operadores do sistema e ao incentivo do uso das informações geradas.

Pode ser observado neste estudo que os benefícios gerados seriam a preservação de dados históricos - através do DW -, a obtenção e cruzamento de dados de diversas origens, o tempo de execução baixo, a geração de relatórios e a facilidade de uso do sistema. Este deve gerar relatórios padronizados e os custos dos processos julgados das $1^{\text {a e }} 2^{\mathrm{a}}$ instâncias. O SICJT e SICTRT4 têm quatro fases de implantação: preparatória, modelagem, projetos pilotos e aperfeiçoamento e implantação.

No SICTRT4, por sua vez, é defendido o uso dos Métodos de Custeio Direto ou ABC, com cinco centros de custos - as unidades do $1^{\circ} \mathrm{Grau}$, as unidades do $2^{\circ} \mathrm{Grau}$, o Apoio Judiciário, o Apoio Administrativo e as Áreas Autônomas. Os custos indiretos seriam rateados na área judiciária com base no número de processos julgados e na área administrativa pela quantidade de pessoal. O sistema geraria ganhos de produtividade e de transparência, facilitaria a avaliação dos gestores públicos e possibilitaria a comparação entre unidades internas e externas.

Constata-se, na pesquisa realizada, que os desafios para a implantação são as dificuldades orçamentárias, a resistência a mudanças, a falta de sistemas específicos e a escassez de conhecimento e de divulgação do sistema por parte da administração. Entretanto, destaca-se que o sistema deverá gerar informações confiáveis, relatórios, informações sobre as unidades internas e seus padrões e o custo para produção de imóveis no órgão, bem como o custo do processo julgado pelas instâncias ( $1^{\mathrm{a}} \mathrm{e} 2^{\mathrm{a}}$ ). Para atingir tais finalidades é necessária a organização do sistema, e o pleno conhecimento das normas e dos sistemas.

Desse modo, mediante a iminente implantação do SICTRT4, este estudo contribui para que os gestores e administradores vislumbrem as necessidades relativas ao sistema e suas especificidades em relação ao SICJT, a fim de realizarem futuras melhorias. As limitações do estudo se referem ao número restrito de gestores do órgão que responderam à entrevista e a realização do trabalho em apenas um dos Tribunais Regionais.

Para estudos futuros, sugere-se que, depois de implantado o sistema de custos em todos os órgãos da Justiça do Trabalho, sejam realizados estudos apontando as diferenças entre o sistema desenhado inicialmente e a sua realidade diária. Estas comparações permitiriam apontar os benefícios gerados pelo SICJT, as dificuldades de implantação, as informações geradas, o método de custeio utilizado e seus centros de custos. Além disso, viabilizaria a verificação da observância da utilização das informações do sistema para o processo decisório e da majoração da transparência das entidades. 


\section{REFERÊNCIAS}

AL-OMIRI, M.; DRURY, C. A survey of factors influencing the choice of product costing system in UK organizations. Management Accounting Research, London, v. 18, n. 4, p. 399-424, Mar.2007. Disponível em: <http:// www.sciencedirect.com/science/article/pii/S1044500507000121>. Acesso em: 07 maio 2017.

BEULKE, R.; BERTÓ, D. J. Custos na administração pública. Revista do Conselho Regional de Contabilidade do Rio Grande do Sul-CRC/RS, Porto Alegre, p. 27-34, ago. 2005. Disponível em: <http://www.iab. com.br/imagens/estilo_iab/img/custos_adm_publica.pdf>. Acesso em: 12 jun. 2017.

BRASIL. Conselho Superior da Justiça do Trabalho - CSJT. Resolução CSJT n. 145, de 28 de novembro de 2014. Aprova o plano estratégico da Justiça do Trabalho para o ano de 2015 a 2020 e dá outras providências. Brasília, DF, 2014. Disponível em: <http://www.csjt.jus.br/c/document_library/get_file?uuid=ac2e46ba-1312-4a16-8dc6-979fd229a1fd\&groupld=955023>. Acesso em: 24 jun. 2017.

Lei n 4.320, de 17 de março de 1964. Estatui Normas Gerais de Direito Financeiro para elaboração e controle dos orçamentos e balanços da União, dos Estados, dos Municípios e do Distrito Federal. Brasília, DF, 1964. Disponível em:<http://www.planalto.gov.br/ccivil_03/leis/L4320.htm>. Acesso em: 24 jun. 2017.

. Constituição (1988). Emenda Constitucional n. 95, de 15 de dezembro de 2016. Altera o Ato das Disposições Constitucionais Transitórias, para instituir o Novo Regime Fiscal, e dá outras providências. Brasília, DF, 2016. Disponível em: <http://www.planalto.gov.br/ccivil_03/constituicao/emendas/emc/emc95. htm>. Acesso em: 30 mai. 2017.

BRIERLEY, J. A. Toward an understanding of the sophistication of product costing systems. Management Accounting Research, London, v. 20, n. 1, p. 61-78, dec. 2008. Disponível em: <http://aaapubs.org/doi/ abs/10.2308/jmar.2008.20.s-1.61?code=aaan-site\&journalCode=jmar>. Acesso em: 07 mai. 2017.

CANCIO, A. J. Sistema de Informação de custos da Justiça do Trabalho. Painel apresentado no IV Congresso Internacional de Informação de Custos e Qualidade do Gasto no Setor Público. Anais... Brasília, DF, 2014. Disponível em: <http://www.socialiris.org/ivcongressocq/materiais/Painel5CANCIO.pdf>. Acesso em: 10 mai. 2017.

CARDOSO, R. L.; AQUINO, A. C. B. de; BITTI, E. J. da S. Reflexões para um framework da informação de custos do setor público brasileiro. Revista de Administração Pública, Rio de Janeiro, v. 45, n. 5, p. 1565-586, set./out. 2010. Disponível em: <http://www.scielo.br/scielo.php?script=sci_arttext\&pi$d=$ S0034-76122011000500014>. Acesso em: 02 set. 2016. 
CONSELHO FEDERAL DE CONTABILIDADE. Resolução CFC n. 1.366/2011, de 02 de dezembro de 2011. Aprova a NBC T 16.11 - Sistema de Informação de Custos do Setor Público. Brasília, DF, 2011. Disponível em: <http://www1.cfc.org.br/sisweb/SRE/docs/RES_1366.doc>. Acesso em: 01 jun. 2016.

DRURY, C.; TAYLES, M. Explicating the design of overhead absorption procedures in UK organizations. The British Accounting Review, v. 37, n. 1, p. 47-84, mar. 2005. Disponível em: <http://www.sciencedirect.com/ science/article/pii/S0890838904000733>. Acesso em: 07 mai. 2017.

GEIGER, D. R.; ITTNER, C. D. The influence of funding source and legislative requirements government cost accounting practices. Accounting, Organizations and Society, Oxford, v. 21, n. 6, p. 549-567, aug. 1996. Disponivel em: <http://www.sciencedirect.com/science/article/pii/0361368296000086>. Acesso em: 07 mai. 2017.

GIL, A. C. Métodos e técnicas de pesquisa social. 6. ed. São Paulo: Atlas, 2009.

GOSSELIN, M.; HENRI, J. F.; LAURIN, C. Costing governmental services in a reformed environment: unreachable goal or unfinished business? Canadian Public Administration, Toronto, v. 58, n. 3, p. 384-405, sep. 2015. Disponível em: <http://onlinelibrary.wiley.com/doi/10.1111/capa.12116/abstract>. Acesso em: 02 ago. 2016.

HONDA, A. B. B. Influência do Sistema de Custos na qualidade do gasto público. Caderno de Finanças Públicas, n. 11, p. 187-208, dez. 2011. Disponível em: <http://www.esaf.fazenda.gov.br/assuntos/biblioteca/ cadernos-de-financas-publicas-1/influencia.pdf>. Acesso em: 12 ago. 2016.

INTERNATIONAL FEDERATION OF ACCOUNTANTS. Perspective on cost accounting for government: international public sector study. New York, 2000. Disponível em: <http://www.fasab.gov/pdffiles/ifac_perspectives.pdf>. Acesso em: 13 jun. 2016.

JOIA, L. A.; MAGALHÃES, C. Evidências empíricas da resistência à implantação de prescrição eletrônica: uma análise explano-exploratória. RAC-Eletrônica, Curitiba, v. 3, n. 1, p. 81-104, 2009. Disponível em: <https:// pdfs.semanticscholar.org/b35b/07e4707535c8cab314c5d7da39b041956e6b.pdf>. Acesso em: 12 jun. 2017.

KIM, H.; KANKANHALLI, A. Investigating user resistance to information systems implementation: a status quo bias perspective. MIS Quarterly, Minneapolis, v. 33, n. 3, p. 567-582, 2009. Disponível em: <http://misq.org/ investigating-user-resistance-to-information-systems-implementation-a-status-quo-bias-perspective.html>. Acesso em: 12 jun. 2017. 
LAPOINTE, L.; RIVARD, S. A multilevel model of resistance to information technology implementation. MIS Quarterly, Minneapolis, v. 29, n. 3, p. 461-491, 2005. Disponível em: <http://misq.org/a-multilevel-model-of-resistance-to-information-technology-implementation.html>. Acesso em: 12 jun. 2017.

LAPSLEY, I.; WRIGHT, E. The diffusion of management accounting innovations in the public sector: a research agenda. Management Accounting Research, London, v. 15, n. 3, p. 355-374, sept. 2004. Disponível em: <http://www.sciencedirect.com/science/article/pii/S104450050400040X>. Acesso em: 07 mai. 2017.

LORENZATO, N. T.; BEHR, A.; GOULARTE, J. L. L. Benefícios e problemas na implantação de um sistema de informação de custos do setor público no estado do Rio Grande do Sul. Revista ConTexto, Porto Alegre, v. 16, n. 32, p. 126-141, jan./abr. 2016. Disponível em: <http://seer.ufrgs.br/index.php/ConTexto/article/ view/66327>. Acesso em: 14 ago. 2016.

LOVATO, E. L. Sistema de Informações de Custos no Setor Público: percepção dos usuários sobre a adoção, implementação e utilidade das informações de custos na gestão e desenvolvimento municipal. 2015. 138f. Dissertação (Mestrado em Planejamento e Governança Pública) - Programa de Pós-Graduação em Planejamento e Governança Pública, Universidade Tecnológica Federal do Paraná, Curitiba, 2015. Disponível em: <http://repositorio.utfpr.edu.br/jspui/bitstream/1/1155/1/CT_PPGPGP_M_Lovato\%2c\%20Ederson\%20 Luiz_2015.pdf> Acesso em: 02 set. 2016.

MACHADO, N. Sistema de informação de custo: diretrizes para integração ao orçamento público e à contabilidade governamental. 2002. 221f. Tese (Doutorado em Controladoria e Contabilidade) - Curso de Pós-graduação em Contabilidade e Controladoria, Faculdade de Economia, Administração e Contabilidade, Universidade de São Paulo, São Paulo, 2002. Disponível em: <http://www.tesouro.fazenda.gov.br/documents/10180/391196/Nelson_Machado_Tese_Doutorado.pdf/cce9664a-4467-4ea5-91c0-62e0fa3f16c6> Acesso em: 06 jun. 2016.

MACHADO, N.; HOLANDA, V. B. de. Diretrizes e modelo conceitual de custos para o setor público a partir da experiência do governo federal do Brasil. Revista de Administração Pública, Rio de Janeiro, v. 44, n. 4, p. 791-820, jul./ago. 2010. Disponível em: <http://www.scielo.br/pdf/rap/v44n4/v44n4a03.pdf>. Acesso em: 30 nov. 2016.

MARTINS, E. Contabilidade de custos. 10 ed. São Paulo: Atlas, 2010.

MAUSS, C. V.; SOUZA, M. A. de. Gestão de custos aplicada ao setor público. São Paulo: Atlas, 2008. 
PEROTTONI, R. et al. Sistemas de informações: um estudo comparativo das características tradicionais às atuais. ReAd, Porto Alegre, v. 7, n. 3, p. 1-15, 2001. Disponível em: <http://gianti.ea.ufrgs.br/files/artigos/2001/2001_102_ReAd.pdf>. Acesso em: 04 mai. 2017.

RAUPP, F. M.; BEUREN, I. M. Metodologia da pesquisa aplicável às ciências sociais. In: BEUREN, I. M. et al.

Como elaborar trabalhos monográficos em contabilidade. 3. ed. São Paulo: Atlas, 2013. p. 76-97.

REMÍGIO, H. G. Custos no serviço público - um modelo aplicado ao custeio dos processos judiciais. 2002. 154 f. Dissertação (Mestrado em Contabilidade) - Programa Multiinstitucional e Inter-regional de Pós-graduação em Ciências Contábeis, Universidade de Brasília, Brasília, 2002. Disponível em: <http:www.cca.unb.br/ images/dissert_mest/mest_dissert_009.pdf>. Acesso em: 07 jun. 2016.

RICHARDSON, R. J. Pesquisa social: métodos e técnicas. 6. ed. São Paulo: Atlas, 1999.

SANTOS, E. F. dos. Subsistema de mensuração e acumulação de custos no Setor Público: uma contribuição, em conformidade com a NBC TSP 16.11. 2014. 139f. Dissertação (Mestrado em Ciências Contábeis) - Programa de Pós-Graduação em Ciências Contábeis, Fundação Instituto Capixaba de Pesquisa em Contabilidade, Economia e Finanças, Vitória, 2014. Disponível em: <http://www.fucape.br/_public/producao_cientifica/8/Disserta\%C3\%A7\%C3\%A30\%20Elisangela\%20Fernandes\%20dos\%20Santos.pdf>. Acesso em: 12 set. 2016.

SCHOUTE, M.; BUDDING, T. Stakeholders' Information Needs, Cost System Design, and Cost System Effectiveness in Dutch Local Government. Financial Accountability \& Management, Oxford, v. 33, n. 1, p. 77 101, may. 2017. Disponível em: <http://onlinelibrary.wiley.com/doi/10.1111/faam.12116/abstract>. Acesso em: 07 mai. 2017.

SOUZA, M. A. de; CARVALHO, M. P. Implantação de sistemas de custos no setor público: um estudo em municípios do Rio Grande do Sul face às determinações da STN e do CFC. In: CONGRESSO ASSOCIAÇÃO NACIONAL DOS PROGRAMAS DE PÓS-GRADUAÇÃO EM CIÊNCIAS CONTÁBEIS, 6., 2012, Florianópolis. Anais... Florianópolis: ANPCONT, 2012. Disponível em: <http://congressos.anpcont.org.br/congressos-antigos/vi/images/ ccg\%2094.pdf>. Acesso em: 31 ago. 2016.

TRIBUNAL REGIONAL DO TRABALHO DA 4a REGIÃO. Poder Judiciário. Justiça do Trabalho. Porto Alegre, 2016. Disponível em: <http://www.trt4.jus.br/portal/portal/trt4/institucional/justicaTrabalho>. Acesso em: 23 jun. 2016. 
Poder Judiciário. Resolução administrativa no 04/2015. Aprova o Plano Estratégico do Tribunal Regional do Trabalho da 4a Região para o quinquênio 2015/2020. Porto Alegre, 2015. Disponível em: <https://www.trt4.jus.br/PortariasProvimentosPortlet/download/653101/RA_04-2015_-_com_anexo_-_para_o_site.pdf>. Acesso em: 22 ago. 2016

VERBEETEN, F. H. Public sector cost management practices in The Netherlands. International Journal of Public Sector Management, Bradford, v. 24, n. 6, p. 492-506, 23 aug. 2011. 